International Journal of Current Advanced Research

ISSN: O: 2319-6475, ISSN: P: 2319 - 6505, Impact Factor: SJIF: 5.995

Available Online at www.journalijcar.org

Volume 6; Issue 5; May 2017; Page No. 3664-3669

DOI: http://dx.doi.org/10.24327/ijcar.2017.3669.0343

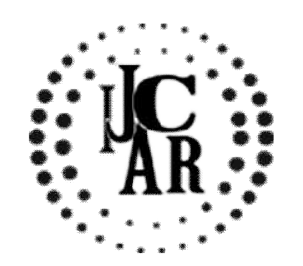

Research Article

\title{
A COMPARATIVE ASSESSMENT OF 75G AND 100G ORAL GLUCOSE TOLERANCE TEST IN DIAGNOSING GESTATIONAL DIABETES
}

\author{
G Shanti Sneha., E Swathi and Mohammed Ismail Khan*
}

Department of Obstetrics and Gynaecology, ESIC Medical College, Sanathnagar Hyderabad

\section{A R T I C L E I N F O}

\section{Article History:}

Received $20^{\text {th }}$ February, 2017

Received in revised form $12^{\text {th }}$ March, 2017

Accepted $15^{\text {th }}$ April, 2017

Published online $28^{\text {th }}$ May, 2017

\section{Key words:}

Oral glucose challenge test, oral glucose tolerance test, $75 \mathrm{~g}, 100 \mathrm{~g}$, gestational diabetes mellitus

\begin{abstract}
A B S T R A C T
Background: Gestational Diabetes mellitus (GDM) has potential threatening and undesirable consequences in terms of maternal, foetal, perinatal and neonatal outcomes. Diagnosing GDM could be tricky and confusing given the large number of available criteria. The study was taken up to study the diagnostic characteristics of $75 \mathrm{~g}$ vs. $100 \mathrm{~g}$ oral glucose tolerance test (OGTT) read with ADA-2015 and Carpenter Coustan criteria respectively.
\end{abstract}

Methods: 140 Patients between $24-28$ weeks gestation with abnormal 50g oral glucose challenge test were randomized to group $\mathrm{A}$ and $\mathrm{B}$ after excluding pre gestational diabetes. Group A was administered a 75g OGTT and group B was given $100 \mathrm{~g}$ OGTT. Plasma glucose values were measured at 1st and 2nd hour in group A and 1st, 2nd and 3rd hour in group B.

Results: The $100 \mathrm{~g}$ OGTT diagnosed $28.57 \%$ patients with impaired glucose tolerance (IGT) to have GDM whereas $75 \mathrm{~g}$ OGTT diagnosed $25.71 \%$ of IGT patients to have GDM. The mean plasma glucose levels in $\mathrm{mg} / \mathrm{dl}$ at $1 \mathrm{st}$ and 2 nd hour in IGT patients was significantly higher in $100 \mathrm{~g}$ OGTT ( $1 \mathrm{st}$ hr: $151.82 \pm 24.05$ vs. $163.29 \pm 38.68$; P-0.03), (2nd hr: $131.96 \pm 27.36$ vs $142.7 \pm 32.96$; P-0.03). Mean plasma in $\mathrm{mg} / \mathrm{dl}$ in GDM cases varied significantly after $75 \mathrm{~g}$ and $100 \mathrm{~g}$ glucose loads (1st hr: $172 \pm 23.55$ vs $190.75 \pm 27.05$; P0.03 ), (2nd hr: $161.61 \pm 14.72$ vs $179.35 \pm 26.75$; P-0.01). 5 and 11 patients met or exceeded abnormal values in 1 st hour with $75 \mathrm{~g}$ OGTT and $100 \mathrm{~g}$ OGTT (P-0.08) respectively. In the second hour 11 patients showed abnormal values in group A compared to 19 patients in group B (P-0.01). In addition, 9 patients in 100g OGTT group showed abnormal values at 3rd hour.

Conclusion: The 100g OGTT appears to be more sensitive than 75g OGTT. It is preferable to diagnose a patient as GDM and treat her appropriately rather than missing a diagnosis, using a criteria with higher thresholds or lower glucose load. Further studies comparing the outcomes with different diagnostic criteria need to be taken up in quest of one single worldwide criterion applicable and acceptable to most populations.

Copyright $(2017$ G Shanti Sneha., E Swathi and Mohammed Ismail Khan. This is an open access article distributed under the Creative Commons Attribution License, which permits unrestricted use, distribution, and reproduction in any medium, provided the original work is properly cited.

\section{INTRODUCTION}

Gestational diabetes mellitus (GDM) has been defined as any degree of glucose intolerance with first recognition in pregnancy which may or may not resolve after pregnancy. In 2008, the International Association of Diabetes and Pregnancy Study Groups (IADPSG) consensus panel introduced criteria to differentiate gestational onset of diabetes from pre gestational diabetes, also referred to as overt diabetes [1]. These criteria ensured that women with overt diabetes are detected in early pregnancy to ensure

*Corresponding author: Mohammed Ismail Khan

Department of Obstetrics and Gynaecology, ESIC Medical

College, Sanathnagar Hyderabad institution of appropriate diabetic care at the earliest as these patients and their foetuses are at a higher risk of morbidity and mortality. The prevalence of diabetes is ever increasing in the world. It has been estimated that the prevalence of diabetes would reach 366 million in the year 2030 from 171 million in the year 2000 [2]. India has recorded the highest number of diabetes cases in the world and it has been projected that the prevalence in 2030 would be 79.4 million from 31.7 million in 2000 [3]. The country has hence been designated by the World Health Organisation as the diabetes capital of the world. A variation in prevalence is noted in urban and rural population with urban populations reporting around $10-16 \%$ prevalence while rural populations reporting around $2-4 \%$ [4]. These statistics are of concern to the obstetrician because an increase in prevalence implies a 
higher prevalence in obstetric population and hence the inherent increase in associated maternal, foetal and perinatal morbidity and mortality. Diabetes in pregnancy complicates maternal health by causing and / or aggravating microvascular damage like retinopathy and nephropathy in addition to neuropathy and increasing the possibility of ketoacidosis. These complications are predominantly seen in pregestational diabetics whereas they are significantly less frequent in GDM [5]. Obstetric complications like pre eclampsia, hydramnios, increased operative interference and malpresentations are replete in patients with GDM [6]. Foetal and perinatal complications like still births, macrosomia and preterm births is found to occur in both pre gestational and gestational diabetes [7], whereas congenital anomalies are predominantly noted in overt cases [8]. Several morbidities further complicate the neonatal health which, include hypoglycemia, hypocalcaemia, hypomagnesaemia, polycythemia, hyperbilirubinaemia, neuro developmental disorders and the sequelae of traumatic birth injuries. Present estimates figure about $1-14 \%$ of all pregnancies being affected with GDM, variation attributed to population distribution and diagnostic criteria employed [9]. The increasing incidence and the undesirable outcomes of GDM warrant early diagnosis and appropriate treatment. The diagnosis of GDM is controversial and there is no general consensus on the criteria to be used [10]. This signifies the need for a screening test for GDM. Though the American diabetes association (ADA) recommends only high risk patients to be screened for GDM [11], several studies have reported a $50 \%$ chance of missing the diagnosis by such high risk testing [12]. Hence several authors advocate routine screening of all antenatal mothers especially in South East Asian countries, particularly in India owing to higher prevalence and genetic predisposition [6]. The most commonly employed screening test is the oral glucose challenge test (OGCT) using 50g glucose followed an hour later by assessment of venous plasma glucose levels [5].

An abnormal OGCT is to be followed by oral glucose tolerance test (OGTT). There is no general agreement on the amount of glucose to be used and the values to be used for interpretation. Though there are several criteria, the generally accepted and most commonly employed ones are the $75 \mathrm{~g}$ OGTT (2hrs) and 100g OGTT ( $3 \mathrm{hrs}$ ) read in accordance with the ADA and Carpenter \& Coustan (CC) criteria respectively. The study was conducted to differentially evaluate the characteristics of $75 \mathrm{~g}$ and $100 \mathrm{~g}$ OGTT in women with impaired glucose tolerance (IGT). The primary outcomes essentially included the comparison of diagnostic behaviors of both the criteria as this is pertinent in diagnosing a mother as GDM which would further determine the therapeutic measures taken to keep the blood sugars in normal range for an uneventful pregnancy, parturition and good outcomes in perinatal and neonatal period.

\section{PATIENTS AND METHODS}

The study was conducted as a longitudinal comparative study at ESIC Medical College Hospital which is a tertiary care teaching hospital with referrals from 35 ESIC hospitals and dispensaries. The study was taken up after approval from the Institutional Ethics Committee and patients were recruited after obtaining an informed consent. Antenatal mothers with $24-28$ weeks gestation were considered for the study. As a protocol all mothers underwent a fasting and post lunch plasma glucose evaluation at the first antenatal visit in first trimester. All antenatal mothers within this gestational age bracket underwent a 50g OGCT as a protocol irrespective of the presence or absence of risk factors. Out of the 3257 patients screened over a year, 160 patients were found to have abnormal OGCT results. Of these 160 patients there was an attrition of 12 patients after OGCT and 8 patients didn't give consent. Hence 140 patients were recruited for the study. The patients were randomly categorized into two groups with the aid of a computer generated table of random numbers. Both the groups were taken for an OGTT immediately on the next alternate day. Group A patients underwent a $75 \mathrm{~g}$ OGTT and group B patients underwent a 100g OGTT.

The OGCT was performed in the ward itself with $50 \mathrm{~g}$ glucose given as a solution in $200 \mathrm{ml}$ water to be consumed within 5 minutes. The test was performed irrespective of the fasting or fed status of the mother. The patient was not allowed to have foods and drinks for the next hour. Blood was collected from the antecubital vein an hour later. A vacutainer with sodium fluoride and potassium oxalate $(5 \mathrm{mg}+4 \mathrm{mg})$ as anticoagulants and glycolytic inhibitors was used. The tests were read as given in table 1 「51

Table 1 OGCT Screening Characterisation

\begin{tabular}{ccc}
\hline S.No. & Characterisation & Criteria \\
\hline 1. & Normal / NGT & $1 \mathrm{hr}$ OGCT $<140 \mathrm{mg} / \mathrm{dl}$ \\
2. & Abnormal / IGT & $1 \mathrm{hr}$ OGCT $\geq 140 \mathrm{mg} / \mathrm{dl}$ \\
\hline NGT - Normal Glucose Tolerance & IGT - Impaired Glucose \\
Tolerance
\end{tabular}

The OGTT was performed after 8 hours of fasting. A baseline fasting blood sugar analysis was done for all patients before proceeding to the OGTT. Patients in group A were administered $75 \mathrm{~g}$ glucose in $300 \mathrm{ml}$ water and were made to sit for $2 \mathrm{hrs}$ and venous blood samples were collected from the antecubital vein in sodium fluoride and potassium oxalate vacutainers at 60 and 120 minutes. The values were read in accordance with the 2015 ADA guidelines [13] as noted in table 2. GDM was diagnosed in this group if any of the three criteria were met or exceeded. Similarly patients in group B were administered $100 \mathrm{~g}$ glucose in $300 \mathrm{ml}$ water and samples were collected at 60,120 and 180 minutes. These values were interpreted in accordance with 1982 Carpenter and Coustan criteria [14] as noted in table 3. GDM was diagnosed in this group when any two of the four mentioned guidelines were met or exceeded.

Table 2 ADA Criteria - 75g OGTT (2011)

\begin{tabular}{ccc}
\hline S.No. & Characterisation as GDM & Criteria \\
\hline 1. & Fasting & $\geq 95 \mathrm{mg} / \mathrm{dl}$ \\
2. & $1 \mathrm{hr}$ OGTT & $\geq 180 \mathrm{mg} / \mathrm{dl}$ \\
3. & $2 \mathrm{hr}$ OGTT & $\geq 155 \mathrm{mg} / \mathrm{dl}$ \\
\hline
\end{tabular}

Table 3 Carpenter and Coustan Criteria - 100g OGTT (1982)

\begin{tabular}{ccc}
\hline S.No. & Characterisation as GDM & Criteria \\
\hline 1. & Fasting & $\geq 95 \mathrm{mg} / \mathrm{dl}$ \\
2. & $1 \mathrm{hr}$ OGTT & $\geq 180 \mathrm{mg} / \mathrm{dl}$ \\
3. & $2 \mathrm{hr}$ OGTT & $\geq 155 \mathrm{mg} / \mathrm{dl}$ \\
4. & $3 \mathrm{hr}$ OGTT & $\geq 140 \mathrm{mg} / \mathrm{dl}$ \\
\hline
\end{tabular}

All the blood glucose analysis was done for plasma by glucose oxidase peroxidase method. Automatic glucometers were altogether avoided. The samples were preserved in appropriate glycolytic inhibitors and were stored in the laboratory at $\left(-4^{\circ} \mathrm{C}\right)$ and were processed within 3 hours of receipt. 


\section{Inclusion Criteria}

- $\quad$ Age $18-35$ years

- Gestational age $24-28$ weeks ( assessed by first trimester scan findings)

- $\quad$ Singleton pregnancy

- Abnormal 1hr 50g OGCT ( $\geq 140 \mathrm{mg} / \mathrm{dl})$

\section{Exclusion Criteria}

- Multifoetal gestation

- Coexisting endocrine and / or medical co morbidities

- Coexisting obstetric disorders / high risk pregnancy

- Patients on gestational progesterones (pharmacologic preparations)

- Pre gestational diabetes at initial antenatal visit/s before 20 week [9]

* $\mathrm{HbA} 1 \mathrm{C} \geq 6.5 \%$

* Fasting plasma sugars $\geq 126 \mathrm{mg} / \mathrm{dl}$

* $2 \mathrm{hr}-75 \mathrm{~g}$ OGTT $\geq 200 \mathrm{mg} / \mathrm{dl}$

* Random Plasma sugars $\geq 200 \mathrm{mg} / \mathrm{dl}$

Qualitative data was statistically analysed using Chi Square test using online software at www.socscistatistics.com and quantitative data was analysed using unpaired t test using online software at www.graphpad.com. Comparisons were done calculating percentages. Coefficient of variance or relative standard deviation was calculated using the formula $C \nu=\frac{\sigma}{\mu}$, where $\sigma$ is the standard deviance and $\mu$ is the mean and equated to a proportion.

\section{Research Involving Human Participants}

1. All procedures performed on the patient were in accordance with the ethical standards of the institutional and national research committee and with the 1975 Helsinki declaration and its latest amendment in 2000 and other comparable ethical standards.

2. All treatment protocols followed are in accordance with the latest accepted Evidence Based Medicine Norms

\section{RESULTS}

The demographic characteristics of both the groups have been tabulated in table 4 below. Differences between age, parity and $\mathrm{BMI}$ are statistically insignificant. Hence both the groups are comparable.

Table 4 Demographic characteristics of both the groups

\begin{tabular}{|c|c|c|c|c|c|}
\hline S.No. & Parameter & Variable & $\begin{array}{c}\text { Group A } \\
75 \mathrm{~g} \text { OGTT }\end{array}$ & $\begin{array}{c}\text { Group B } \\
\text { 100g OGTT }\end{array}$ & $\mathbf{P}$ \\
\hline \multirow{5}{*}{1.} & \multirow{4}{*}{ Age } & $<20$ years & 11 & 8 & \multirow{4}{*}{0.4} \\
\hline & & $21-25 \mathrm{yrs}$ & 42 & 40 & \\
\hline & & $26-30 \mathrm{yrs}$ & 14 & 21 & \\
\hline & & $31-35$ yrs & 3 & 1 & \\
\hline & \multicolumn{2}{|c|}{ Mean Age $(\mathrm{M} \pm \mathrm{SD})$} & $22.9 \pm 2.83$ & $23.6 \pm 2.9$ & 0.15 \\
\hline \multirow{2}{*}{2.} & \multirow{2}{*}{ Parity } & Primi & 26 & 32 & \multirow{2}{*}{0.3} \\
\hline & & Multi & 44 & 38 & \\
\hline \multirow{4}{*}{3.} & & $<18.5 \mathrm{~kg} / \mathrm{m}^{2}$ & 2 & 2 & \multirow{4}{*}{0.68} \\
\hline & & $\begin{array}{c}18.5-24.9 \\
\mathrm{~kg} / \mathrm{m}^{2}\end{array}$ & 62 & 62 & \\
\hline & $\begin{array}{l}\text { Body Mass } \\
\text { Index }\end{array}$ & $\begin{array}{c}25.0-29.9 \\
\mathrm{~kg} / \mathrm{m}^{2}\end{array}$ & 3 & 5 & \\
\hline & & $\begin{array}{c}30.0-34.9 \\
\mathrm{~kg} / \mathrm{m}^{2}\end{array}$ & 3 & 1 & \\
\hline
\end{tabular}

Patients diagnosed as having gestational diabetes with $75 \mathrm{~g}$ and $100 \mathrm{~g}$ OGTT is shown in the table $5.18(25.71 \%)$ mothers were diagnosed as GDM with the $75 \mathrm{~g}$ OGTT whereas a higher percentage (28.57) of mothers were diagnosed to have GDM with $100 \mathrm{~g}$ OGTT when their results were interpreted with CC criteria.

Table 5 Diagnostic Characteristics of three criteria

\begin{tabular}{ccccc}
\hline S.No. & Diagnosis & Group A & Group B & P \\
\cline { 1 - 4 } 1. & GDM n(\%) & $18(25.71)$ & $20(28.57)$ & \multirow{2}{*}{0.7} \\
2. & IGT n(\%) & $52(74.28)$ & $50(71.42)$ & \\
\hline
\end{tabular}

Table 6 below shows the comparison of plasma blood glucose levels $(\mathrm{M} \pm \mathrm{SD})$ of both the groups. The fasting plasma glucose values are not significantly different hence the groups are comparable. The $1 \mathrm{hr}$ and $2 \mathrm{hr}$ OGTT values vary significantly between both the groups with higher values noted with $100 \mathrm{~g}$ OGTT. The coefficient of variance for the same data is illustrated in figure 1.

Table 6 Fasting, $1 \mathrm{hr}$ and $2 \mathrm{hr}$ OGTT values $(\mathrm{M} \pm \mathrm{SD})$ in group A and group B (IGT women)

\begin{tabular}{ccccc}
\hline S.No. & Characteristic & $\begin{array}{c}\text { Group A } \\
(\mathbf{n}=\mathbf{7 0})\end{array}$ & $\begin{array}{c}\text { Group B } \\
(\mathbf{n = 7 0 )}\end{array}$ & P value \\
\hline 1. & Fasting $(\mathrm{mg} / \mathrm{dl})$ & $92.42 \pm 21.33$ & $97.68 \pm 28.47$ & 0.21 \\
2. & $1 \mathrm{hr}-$ OGTT $(\mathrm{mg} / \mathrm{dl})$ & $151.82 \pm 24.05$ & $163.29 \pm 38.68$ & 0.03 \\
3. & $2 \mathrm{hr}-$ OGTT $(\mathrm{mg} / \mathrm{dl})$ & $131.96 \pm 27.36$ & $142.7 \pm 32.96$ & 0.03 \\
\hline
\end{tabular}

Figure1: Coefficient of Variance in OGTT values in IGT women

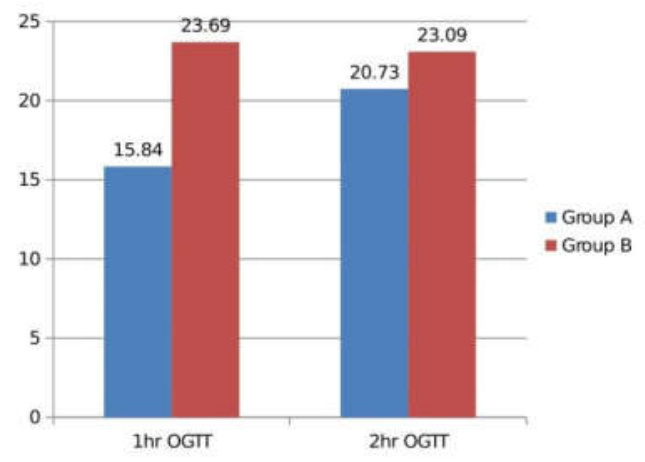

Table 7 compares the fasting, $1 \mathrm{hr}$ and $2 \mathrm{hr}$ OGTT values in women diagnosed as GDM with ADA - 2015 and CC criteria respectively. Fasting levels vary insignificantly between the groups hence they are comparable for OGTT results. OGTT values are significantly higher in $100 \mathrm{~g}$ OGTT compared to $75 \mathrm{~g}$ OGTT at $1^{\text {st }} 2^{\text {nd }}$ hour. The Relative standard deviation of the data is as shown in figure 2

Table 7 Fasting, $1 \mathrm{hr}$ and $2 \mathrm{hr}$ OGTT values $(\mathrm{M} \pm \mathrm{SD})$ in women with GDM

\begin{tabular}{ccccc}
\hline S.No. & Characteristic & $\begin{array}{c}\text { Group A } \\
(\mathbf{n = 1 8})\end{array}$ & $\begin{array}{c}\text { Group B } \\
(\mathbf{n = 2 0})\end{array}$ & P value \\
\hline 1. & Fasting $(\mathrm{mg} / \mathrm{dl})$ & $124.61 \pm 19.22$ & $127.72 \pm 18.28$ & 0.61 \\
2. & $1 \mathrm{hr}-$ OGTT $(\mathrm{mg} / \mathrm{dl})$ & $172.27 \pm 23.55$ & $190.75 \pm 27.05$ & 0.03 \\
3. & $2 \mathrm{hr}-$ OGTT $(\mathrm{mg} / \mathrm{dl})$ & $161.61 \pm 14.72$ & $179.35 \pm 26.75$ & 0.01 \\
\hline
\end{tabular}

Table 8 Differential features in group A

\begin{tabular}{ccccc}
\hline S.No. & Characteristic & $\begin{array}{c}\text { Group A } \\
(\mathbf{n = 7 0 )} \\
\text { Post OGCT }\end{array}$ & $\begin{array}{c}\text { Group A } \\
(\mathbf{n = 1 8})\end{array}$ & P value \\
\hline GDM & \\
\hline 1. & $1 \mathrm{hr}-$ OGTT $(\mathrm{mg} / \mathrm{dl})$ & $151.82 \pm 24.05$ & $172.27 \pm 23.55$ & 0.0018 \\
\hline
\end{tabular}


Figure2: Relative standard deviation in OGTT values in GDM patients

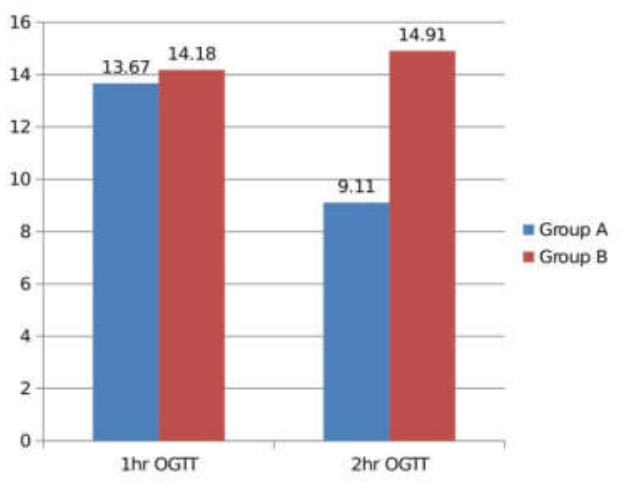

Figure 2 Relative standard deviation in OGTT values in GDM patients

A comparison is made between the mean plasma glucose values at $1^{\text {st }}$ and $2^{\text {nd }}$ hour in IGT groups and the later diagnosed GDM groups. The same is illustrated in table 8 and table 9 ,

Table 9 Differential features in group B

\begin{tabular}{ccccc}
\hline S.No. & Characteristic & $\begin{array}{c}\text { Group A } \\
(\mathbf{n}=\mathbf{7 0}) \\
\text { Post OGCT }\end{array}$ & $\begin{array}{c}\text { Group A } \\
(\mathbf{n}=\mathbf{2 0}) \\
\text { GDM }\end{array}$ & P value \\
\hline 1. & $1 \mathrm{hr}-$ OGTT $(\mathrm{mg} / \mathrm{dl})$ & $163.29 \pm 38.68$ & $190.75 \pm 27.05$ & 0.0039 \\
2. & $2 \mathrm{hr}-$ OGTT $(\mathrm{mg} / \mathrm{dl})$ & $142.7 \pm 32.96$ & $179.35 \pm 26.75$ & 0.0001 \\
\hline
\end{tabular}

Table 10 OGTT characteristics in terms of diagnosis at each step in both the groups

\begin{tabular}{ccccc}
\hline S.No. Characteristic & $\begin{array}{c}\text { Group A } \\
(\mathbf{n = 1 8})\end{array}$ & $\begin{array}{c}\text { Group B } \\
(\mathbf{n = 2 0 )}\end{array}$ & P value \\
\hline 1. & $1 \mathrm{hr}-$ OGTT & 5 & 11 & 0.08 \\
2. & $2 \mathrm{hr}-$ OGTT & 11 & 19 & 0.01 \\
3. & $3 \mathrm{hr}-$ OGTT & - & 9 & - \\
\hline
\end{tabular}

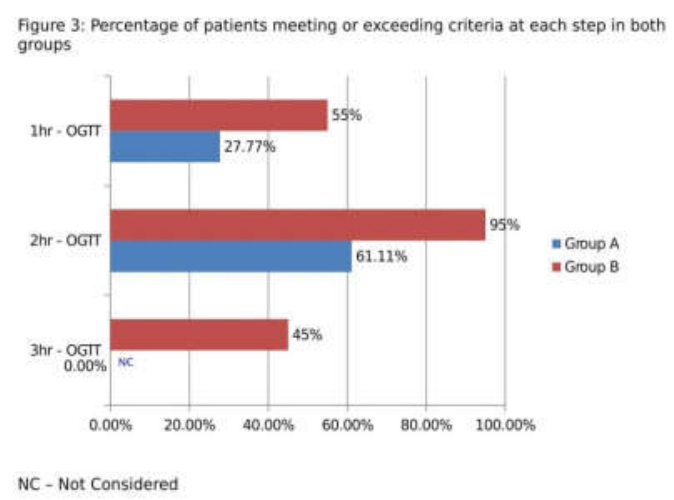

Figure 3 Percentage of patients meeting or exceeding criteria at each step in both groups

\section{DISCUSSION}

Women with GDM are at an increased risk of maternal and perinatal morbidity. In long term they are also at a higher risk of development of type II Diabetes Mellitus in themselves and their children [15]. Most of these complications can be made less severe or avoided if plasma glucose values are maintained within a target range. The most important step towards this would be to diagnose GDM. Several international bodies have set several criteria and revised them several times creating endless options of which criteria is to be used. Still the basic differentiation remains between the $75 \mathrm{~g}$ and $100 \mathrm{~g}$ OGTT which are commonly used. We have selected criteria with same plasma glucose values at fasting, $1^{\text {st }}$ and $2^{\text {nd }}$ hour for both the tests to evaluate the differences brought about by administering different glucose loads. Though the $100 \mathrm{~g}$ OGTT also considers the $3^{\text {rd }} \mathrm{hr}$ plasma glucose value this was not considered for comparison in the $75 \mathrm{~g}$ OGTT group. The fasting plasma glucose of both the groups varied in a statistically insignificant manner hence they were considered comparable.

The percentage of women with IGT diagnosed as GDM with $100 \mathrm{~g}$ OGTT appear to be higher (28.57) compared to $75 \mathrm{~g}$ OGTT (25.71). This appears statistically insignificant. Our findings appear to correlate well with the findings of Olarinoye et al who reported a higher prevalence of GDM with the use of $100 \mathrm{~g}$ OGTT (16). Similar findings were also reported by Giorgio Mello et al with a $7.02 \%$ higher prevalence of GDM when diagnosed with 100g OGTT [17]. Orluwene et al reported a percentage variance of 9.28 with a higher sensitivity favouring 100g OGTT [18].

The difference between hour 1 and hour 2, OGTT values in both the groups was statistically different. The first hour $75 \mathrm{~g}$ OGTT values were less $(151.82 \pm 24.05 \mathrm{mg} / \mathrm{dl})$ than the $100 \mathrm{~g}$ OGTT values $(163.29 \pm 38.68 \mathrm{mg} / \mathrm{dl})$ which appeared statistically significant $(\mathrm{P}-0.03)$. The second hour mean plasma glucose values in IGT women in $100 \mathrm{~g}$ OGTT group was higher compared to $75 \mathrm{~g}$ OGTT $(131.96 \pm 27.36 \mathrm{mg} / \mathrm{dl}$ vs. $142.7 \pm 32.96 \mathrm{mg} / \mathrm{dl})$ which also appeared statistically significant with a $\mathrm{P}$ value of 0.03 . A similar trend was also observed when women with GDM were compared, with respect to their plasma glucose levels at first and second hour. At first hour women tested with $100 \mathrm{~g}$ OGTT showed a mean of $190.75 \pm 27.05 \mathrm{mg} / \mathrm{dl}$ compared to $75 \mathrm{~g}$ OGTT women who showed $172.27 \pm 23.55 \mathrm{mg} / \mathrm{dl}$ (P value -0.03 ). Similarly at second hour also the mean plasma glucose values varied significantly $(\mathrm{P}-0.01)$ with a higher value observed in $100 \mathrm{~g}$ OGTT women $(179.35 \pm 26.75 \mathrm{mg} / \mathrm{dl})$ compared to $75 \mathrm{~g}$ OGTT women $(161.61 \pm 14.72 \mathrm{mg} / \mathrm{dl})$.

Our findings appear to be consistent with Brustman et al who reported significantly higher values at first, second and third hour with 100g OGTT compared to 75g OGTT [19]. Weiss et al compared $1^{\text {st }}$ and $2^{\text {nd }}$ hour findings after $100 \mathrm{~g}$ OGTT and $75 \mathrm{~g}$ OGTT and found plasma glucose levels to be significantly higher in the group with larger glucose load [20]. Olarinoye et al reported higher values with 100g OGTT but this was significant only with the third hour plasma samples but not with the first and second hour samples [16]. Orluwene et al have reported higher values of plasma glucose with $100 \mathrm{~g}$ OGTT but this appeared statistically significant at second hour only [18]. Higher values with 100g OGTT signify that a greater number of women will meet the set criteria which are same for $75 \mathrm{~g}$ and $100 \mathrm{~g}$ OGTT, but a higher load of glucose with similar reference points for interpretation will increase the sensitivity of the test. This was also reflected in our study as more patients were diagnosed with GDM when administered with $100 \mathrm{~g}$ glucose load.

The co efficient of variance at each hour in IGT and GDM women were calculated. A higher relative standard deviation was noted in women who were administered $100 \mathrm{~g}$ glucose load. Percentage variation in relative standard deviation was $39.71 \%$ and $10.77 \%$ at $1^{\text {st }}$ and $2^{\text {nd }}$ hour between group $\mathrm{A}$ and 
$\mathrm{B}$; with higher variance in $100 \mathrm{~g}$ OGTT group. Similarly $3.66 \%$ and $48.29 \%$ variation existed at first and second hour respectively in coefficient of variance calculated for patients with GDM. This represents an uncertain way in which the body handles a $100 \mathrm{~g}$ glucose load compared to $75 \mathrm{~g}$ glucose load in women with IGT and GDM. It would be pertinent to note here that similar effect would be observed with heavier meals and the beneficial effects of having smaller frequent meals as each meal would present a lower glucose load on the metabolic machinery.

A comparison was made within group A and group B. Mean plasma glucose values at first and second hour between 70 patients (with IGT) and 18 patients (diagnosed GDM) in group A was significant which implies that the $75 \mathrm{~g}$ OGTT differentiates well between IGT and GDM. In group B, patients showed statistically significant differences in plasma glucose values when compared to IGT (70 patients) and GDM (20 patients). Hence the $100 \mathrm{~g}$ OGTT also differentiates well between IGT and GDM.

The number of patients who met and exceeded the set criteria was also considered in both the groups. At first hour $27.23 \%$ additional patients showed abnormal plasma glucose values but this is not statistically significant $(\mathrm{P}-0.08)$. At second hour $95 \%$ patients showed abnormal OGTT results with $100 \mathrm{~g}$ but only $61.11 \%$ showed abnormal results with $75 \mathrm{~g}$ glucose load. This appeared statistically significant $(\mathrm{P}-0.01)$. The third hour was considered for 100g OGTT in which $45 \%$ showed abnormal results whereas this was not considered in ADA criteria for $75 \mathrm{~g}$ OGTT. It is quite clear from this that more patients can be 'labeled' GDM with 100g OGTT. A part of the extra contribution would come from the third hour reading in addition to the first and second hour. This appears to be in agreement with higher detection rates with $100 \mathrm{~g}$ OGTT reported by Olarinoye et al [16] and Soonthornpun et al [21]. The WHO has prescribed 75g OGTT for use. Weiss et al have noted that lack of data could be responsible for less patients being assessed and less centers taking up the ADA 2015 criteria for 75g OGTT [20].

\section{CONCLUSION}

It appears from our study that $100 \mathrm{~g}$ OGTT read with CC criteria is a more sensitive method of diagnosing GDM compared to $75 \mathrm{~g}$ OGTT read with ADA-2015 criteria. Though more cases would be diagnosed with the $100 \mathrm{~g}$ OGTT, it is still not clear if this translates into betterment of maternal and perinatal outcomes. Further studies are required to measure specific outcomes with the use of different criteria. The limitations of our study include a small sample size and randomization of groups for different interventions.

\section{Declarations}

Funding: No funding sources

Conflict of interest: None declared

Ethical approval: The study was approved by the Institutional Ethics Committee of ESIC Medical College.

\section{Acknowledgement}

The authors sincerely thank the Dr. M. Srinivas (Dean, ESIC Medical College, Hyd), Dr. T. Madhuri

(Academic Registrar, ESIC MC) and Dr. M. Ashwin Kumar (Incharge, Medical Education Unit, ESICMC), for their continued efforts in our academic growth and enlightenment. The authors also thank the Department of Laboratory Medicine, ESICMC for their co-operation and support.

\section{References}

1. IADPGS Consensus Panel. International Association of Diabetes and Pregnancy Study Group Recommendations on the Diagnosis and Classification of Hyperglycemia in Pegnancy. Diabetes Care. 2010; 33(3):676-682.

2. Sarah, Gojka Anders. Global Prevalence of Diabetes Estimates for the year 2000 and projections for 2030 . Diabetes Care. 2004; 27:1047-1053.

3. Magon N. Gestational diabetes mellitus: Get, set, go From diabetes capital of the world to diabetes care capital of the world. Indian J Endocrinol Metab. 2011; 15:161-169.

4. Verma NP, Mehta SP, Madhu S, Mather HM, Keen H. Prevalence of known diabetes in an urban Indian environment: the Darya Ganj diabetes survey. $\mathrm{Br}$ Med $J$ (Clin Res Ed). 1986; 293(6544):423-424.

5. Renu Misra. Diabetes. Ian Donald's Practical Obstetric Problems $7^{\text {th }}$ Ed. Wolters Kluwer.2016; 7: 122 - 141.

6. P. Reddi Rani, Jasmina Begum. Screening and Diagnosis of Gestational Diabetes Mellitus, Where Do We Stand. Journal of Clinical and Diagnostic Research. 2016; 10(4): 1-4.

7. Hedderson MM, Ferrara A, Sacks DA. Gestational Diabetes Mellitus and Lesser Degrees of Pregnancy Hyperglycemia: Association With Increased Risk of Spontaneous Birth. Obstetrics \& Gynecology. 2003;102(4):850-856.

8. Casson IF, Clarke CA, Howard CV, McKendrick O, Pennycook S, Pharoah POD, et al. Outcomes of pregnancy in insulin dependent diabetic women: results of a five year cohort study. BMJ. 1997; 315:275-278.

9. American diabetes association position statement on diagnosis and classification of diabetes mellitus. Diabetes Care. 2011; 34(1):62-69.

10. Magee MS, Walden CE, Benedetti TJ, Knopp RH. Influence of diagnostic criteria on the incidence of gestational diabetes and perinatal morbidity. JAMA. 1993; 269(5):609-615.

11. American Diabetes Association. Standards of Medical Care in Diabetes. Diabetes Care. 2007; 30(1):S4-41.

12. Griffin ME, Coffey M, Johnson H, Scanlon P, Foley M, Stronge J. Universal versus risk factor based screening for gestational diabetes mellitus detection rates, gestation at diagnosis and outcome. Diabet Med. 2000; 17:26-32.

13. American Diabetes Association. Diabetes management guidelines. Diabetes Care. 2015; 38(1):S1-S93.

14. Carpenter MW, Coustan DR. Criteria for screening tests for gestational diabetes. Am J Obstet Gynecol. 1982; 144:768.

15. Danam P. GDM and subsequent development of overt diabetes mellitus. Dan Med bull. 1988; 45:405 - 500.

16. Olarinoye JK, Ohwovoriole AE, Ajayi GO : Diagnosis of gestational diabetes mellitus in Nigerian pregnant women--comparison between $75 \mathrm{G}$ and $100 \mathrm{G}$ oral glucose tolerance tests; West Afr J Med. 2004;23(3):198-201. 
17. Giorgio Mello,Parretti Elena, Agostino Ognibene, Riccardo Cioni, Lack of Concordance between the 75-g and 100-g Glucose Load Tests for the Diagnosis of Gestational Diabetes Mellitus: The American Association for Clinical Chemistry: 2006 as doi:10.1373/clinchem.2005.058040.

18. C.G.Orluwene, J.D. Ojule. Disparity in Diagnosis of Gestational Diabetes Mellitus Using $75 \mathrm{~g}$ and $100 \mathrm{~g}$ Glucose Load Tests Among Ante-natal Attendees at Madonna University Teaching Hospital, Elele, Rivers State. $2013 ; 3(9): 01-06$
19. Brustman LE, Gela BD, Moore M, Reilly KD, Langer O. Variations in oral glucose tolerance tests: the 100versus 75-g controversy. J. Assoc Acad Minor Phys. $1995 ; 6: 70-72$.

20. Weiss PA, Haeusler M, Kainer F, Purstner P, Haas J. Toward universal screening for gestational diabetes: relationships between Seventy-five and one hundred gram glucose loads and between capillary and venous glucose concentrations. Am J Obstet Gynecol. 1998; 178:830-835.

21. Soonthornpun S, Soonthornpun K, Aksonteing J, Thamprasit A. A comparison between a 75-g and 100 -g oral glucose tolerance test in pregnant women. Int J Gynaecol Obstet. 2003; 81(2):169-173.

\section{How to cite this article:}

G Shanti Sneha et al (2017) ' A Comparative Assessment Of 75g And 100g Oral Glucose Tolerance Test In Diagnosing Gestational Diabetes', International Journal of Current Advanced Research, 06(05), pp. 3664-3669.

DOI: http://dx.doi.org/10.24327/ijcar.2017.3669.0343 